\title{
Rancang Bangun Sistem Informasi Akuntansi Penjualan dan Pembelian Pada Koperasi Karyawan Senayan City Jakarta Menggunakan Metode Waterfall
}

\author{
Hertanto Dwi Kussetiawan ${ }^{1}$, Ahmad Al Kaafi ${ }^{1}$, Rusma Insan Nurachim ${ }^{1}$, Sandra Dewi Saraswati ${ }^{2}$ \\ ${ }^{1}$ Teknik dan Informatika, Sistem Informasi Akuntansi, Universitas Bina Sarana Informatika, Jakarta, Indonesia \\ ${ }^{2}$ Prodi Teknik Informatika, STMIK Nusa Mandiri, Jakarta, Indonesia \\ Email: ${ }^{1}$ herr.hertanto@yahoo.com, ${ }^{2}$ ahmad.akf@bsi.ac.id, ${ }^{3}$ rusma.rsc@bsi.ac.id, ${ }^{4,}{ }^{*}$ sandra.sww@nusamandiri.ac.id
}

\begin{abstract}
Abstrak
Koperasi Karyawan Senayan City merupakan koperasi yang bergerak dibidang simpan pinjam dan sekaligus mengelola unit usaha toko, transaksi pembelian maupun penjualan hanya dicatat dalam format microsoft excel, pada saat transaksi penjualan tidak langsung dicatat sehingga sering terjadi kesalahan. Untuk itu kami menyusun rancang bangun sistem informasi penjualan dan pembelian pada Koperasi Karyawan Senayan City menggunakan javaNetBeans berbasis dekstop, dengan tujuan untuk membuat sebuah sistem yang terkomputerisasi sehingga dapat digunakan oleh pengurus koperasi tersebut. Metodologi pengembangan software yang digunakan dalam penelitian ini antara lain analisa kebutuhan software, desain, code generaion, testing, dan Support. Hasil yang diperoleh dari penetlitian ini adalah kebutuhan akan sistem informasi akuntansi penjualan tunai, penerimaan kas dan laporan penjualan yang dapat membantu pengelola koperasi dalam mengambil sebuah keputusan.
\end{abstract}

Kata Kunci: Sistem Informasi; Pembelian dan Penjualan; Koperasi Karyawan

\section{Abstract}

The Senayan City Employee Cooperative is a cooperative that operates in the field of savings and loans and at the same time manages a shop business unit, buying and selling transactions are only recorded in Microsoft Excel format, when sales transactions are not immediately recorded so mistakes often occur. For this reason, we designed a sales and purchase information system design at the Senayan City Employee Cooperative using desktop-based java NetBeans, with the aim of creating a computerized system so that it could be used by the cooperative management. The software development methodology used in this research includes software requirements analysis, design, code generation, testing, and support. The results obtained from this research are the need for a cash sales accounting information system, cash receipts and sales reports that can assist cooperative managers in making decisions.

Keywords: Information Systems; Purchasing and Sales; Employee Cooperatives

\section{PENDAHULUAN}

Dalam kenyataannya transaksi jual-beli memerlukan manajemen akuntansi, agar perhitungan akuntansi dapat berjalan secara cepat dan akurat, maka dibutuhkan informasi mengenai nota-nota pembelian, penjualan, pembayaran-pembayaran yang dilakukan oleh badan usaha tersebut atau pemasukan dari pelanggan dan diolah dengan sistem informasi. Karena itu dapat diberlakukan strategi keuangan agar dapat mengetahui produk mana yang paling menguntungkan dan mana yang merugikan.

Koperasi merupakan salah satu contoh dari badan usaha, Koperasi mengandung makna "Kerjasama" bersumber dari kata co-operation yang artinya kerjasama[1]. Koperasi merupakan sebuah organisasi yang beranggotakan sekumpulan orang yang saling bekerjasama secara kekeluargaan demi kesejahteraan anggotanya. Koperasi Karyawan Senayan City merupakan koperasi yang bergerak dibidang simpan pinjam dan sekaligus melayani penjualan, untuk perhitungan akuntansi simpan pinjam telah terkomputerisasi namun untuk unit usaha penjualan masih dilakukan secara manual, dimana pencatatan transaksi pembalian maupun penjualan hanya dicatat dalam format microsoft ecxel, pada saat transaksi penjualan tidak langsung dicatat sehingga sering terjadi kesalahan seperti data terselip, data tidak tercatat dan menimbulkan selisih dalam melakukan stokopname dan tentunya perhitungan untung rugi tidak akurat.

Dalam rangka menganalisis dan menyempurnakan penyusunan karya ilmiah ini, penulis mengambil beberapa referensi sebagai acuan yang relevan. Adapun referensi tersebut sebagai berikut:

Pada referensi Aplikasi Sistem Informasi Koperasi Karyawan Pada PT Surya Siam Keramik [2]. Pada penelitian ini Sistem yang berjalan pada koperasi karyawan PT. Surya Siam Keramik diantaranya: pendaftaran anggota koperasi, transaksi penjualan, simpan pinjam dan pembuatan laporan belum memberikan informasi secara tepat dan akurat. Pendaftaran anggota koperasi sering terjadi redudansi data, dan transaksi penjualan di koperasi masih menggunakan buku besar sehingga sering terjadi kesalahan dalam perhitungan. Dengan permasalahan yang ada, maka penelitian ini mengusulkan sistem koperasi berbasis web, menggunakan metode analisis SWOT dan PIECES. Sistem yang diusulkan dapat memudahkan user mencari informasi dan menyusun laporan koperasi dengan baik, format laporan lebih rapi, keamanan data koperasi terjamin karena adanya menu login. Lalu pada referensi sistem Informasi Penjualan Barang Di Koperasi Pada Kantor Oditurat Militer I-02 Medan Berbasis Web [3] dalam penelitian ini menggambarkan tentang bagaimana sistem informasi penjualan pada koperasi otmil 1-02 Medan. Dari penelitian yang penulis dapat bahwa masih melemahnya sistem informasi 
penjualan koperasi pada otmil 1-02 Medan. Dalam melakukan penjualan, pegawai masih menggunakan sistem penjualan secara manual. Seperti mencatat barang masuk dan keluar pada buku penjualan. Maka dari itu perlu dibuat sebuah sistem informasi penjualan koperasi berbasis web agar memudahkan dalam sistem penjualan koperasi antara admin dan user. Metode penelitian yang digunakan adalah metode waterfall. yaitu dalam metode ini dibutuhkan analisis sistem, desain sistem, implementasi, integrasi dan pengujian serta pemeliharaan sistem. Hasil akhir dari sistem ini atau dapat dikatakan dengan output sistem adalah menampilkan hasil transaksi yang telah dilakukan user dan admin.

\section{METODE PENELITIAN}

\subsection{Metode Waterfall}

Metode yang digunakan pada pengembangan perangkat lunak ini menggunakan metode waterfall [4] terbagi menjadi lima tahapan yaitu:

1. Analisa Kebutuhan Software

Pada tahap ini pembuatan sistem diperlukan suatu komunikasi yang bertujuan untuk memahami software yang diharapkan perngguna dan batasan software. Informasi ini biasanya didapat melalui wawancara, survey atau diskusi, informasi tersebut dianalisis untuk mendapatkan data yang dibutuhkan oleh pengguna.

2. Desain

Proses desain menerjemahkan kebutuhan pengguna dalam sebuah dokumen aplikasi yang dapat diperkirakan kualitasnya sebelum proses coding dimulai, proses ini berfungsi sebagai dasar perancangan untuk mengubah data-data dari analis menjadi sebuah rancangan yang terdiri dari rancangan database, software architecture danuser interface.

3. Code Generation

Tahapan ini merupakan lanjutan dari tahapan desain, yaitu mentranslasi desain menjadi sebuah program.Tahap ini menghasilkan suatu program yang sesuai dengan desainnya.

4. Testing

Program yang telah dibuat harus diuji terlebih dahulu untuk memastikan bahwa program layak dari segi logis maupun fungsional. Pengujian ini disamping untuk meminimalisir kesalahan dapat juga untuk menambah kekurangan yang ada.

5. Support

Ini merupakan tahap terakhir dalam model waterfall. Software yang telah jadi dijalankan tetap dilakukan pemeliharaan, pemeliharaan yang dilakukan termasuk dalam memperbaiki kesalahan yang tidak ditemukan pada langkah sebelumnya, perbaikan implementasi unit system dan peningkatan jasa system sebagai kebutuhan baru.

Dari pemaparan di atas dapat digambarkan metode Waterfall sebagai berikut:

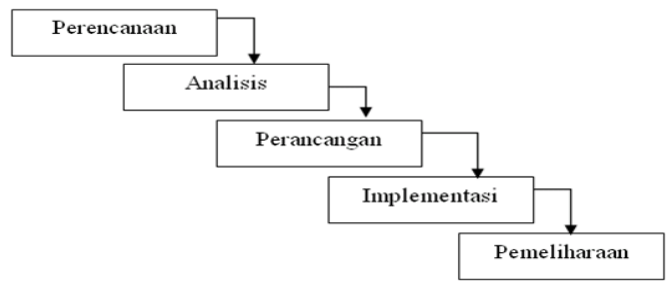

Gambar 1. Tahapan Penelitian Metode Waterfall

\subsection{Konsep Dasar Sistem}

Pengertian Sistem menurut Hutahaean, mengemukakan bahwa "sistem adalah kumpulan dari elemen-elemen yang berinteraksi untuk mencapai suatu tujuan tertentu. Sistem ini menggambarkan suatu kejadian-kejadian dan kesatuan yang nyata adalah suatu objek nyata, seperti tempat, benda, dan orang-orang yang betul-betul ada dan terjadi[5]-[7].

\subsection{Sistem Informasi Akuntansi}

Salah satu sistem yang berkaitan dengan perusahaan atau instansi adalah sistem akuntansi.Pembahasan mengenai sistem akuntansi tidak kalah pentingnya dengan pembahasan bidang akuntansi lainnya. Tanpa sistem akuntansi tidak mustahil kegiatan suatu perusahaan atau instansi akan terganggu. Menurut Mahatmyo, dalam bukunya menjelaskan bahwa :

Sistem akuntansi merupakan suatu rangkaian bukti transaksi, dokumen, catatan-catatan akuntansi, dan laporan-laporan serta alat-alat, prosedur, kebijakan, sumber daya manusia maupun sumber daya lain dalam suatuperusahaan yang dikoordinasikan sedemikian rupa untuk mendukung dalam pencapaian apa yang menjadi tujuan perusahaan. 
Sistem akuntansi meliputi sistem pengolahan informasi akuntansi sejak data direkam dalam dokumen tertentu melalui berbagai sistem pembagian wewenang dalam perusahaan kemudian data diproses dalam media catatan akuntansi sampai dihasilkannya informasi akuntansi.Sistem akuntansi dapat berbeda antara perusahaan yang bergerak dalam bidang pelayanan jasa, perusahaan dagang dan manufaktur. Antara satu jenis perusahaan pun dimungkinkan sistem akuntansinya juga dapat berbeda.

\section{ANALISA DAN PEMBAHASAN}

Dalam penulisan penelitian ini, penulis menggunakan aplikasi UML [8] dalam pemodelan programnya yaitu terdiri dari use case diagram, activity diagram, ERD dan LRS.

\subsection{Use Case Diagram}

Sistem ini memungkinkan user melihat dan mengolah data pada halaman menu utama yang didalamnya terdapat menu Master, menu Transaksi, menu Laporan dan menu Utility. Terdapat 2 (dua) user yaitu Kasir dan Ketua dimana masing-masing dapat melihat dan mengolah data yang ada di halaman utama.

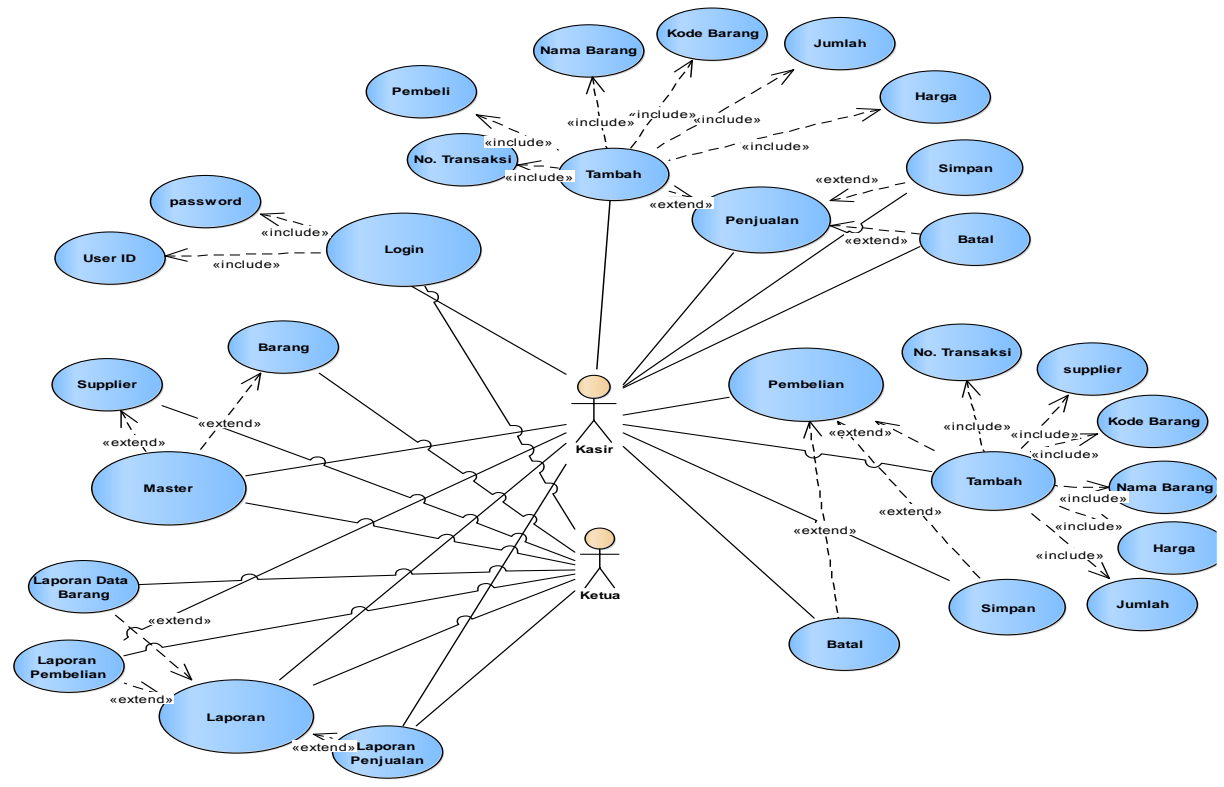

Gambar 2. Use Case Diagram

\subsection{Activity Diagram}

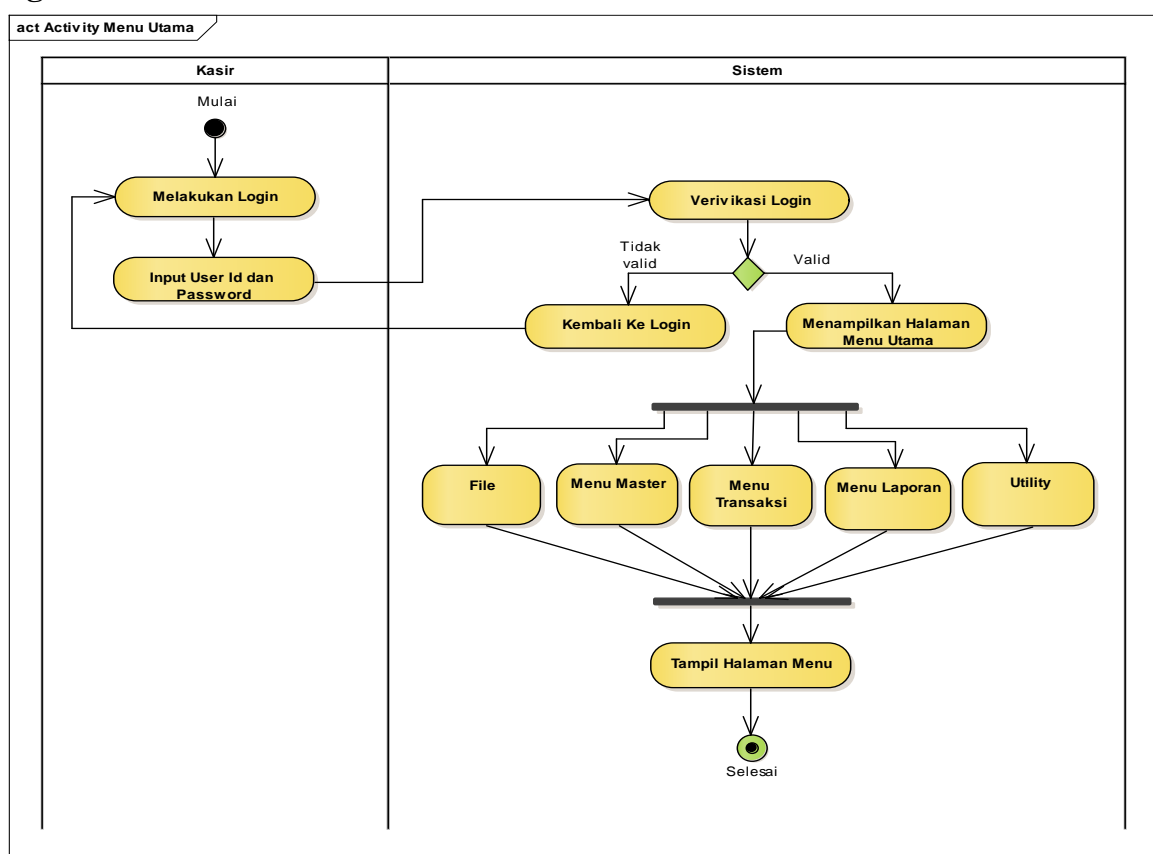

Gambar 3. Activity Diagram 
Pada gambar diatas menjelaskan aksi yang dijalankan oleh aktor dan reaksi yang terjadi pada sistem. Ketika kasir melakukan Login maka sistem akan menampilkan dan memverifikasi data login yang diinput. Jika data benar maka user akan masuk ke halaman menu utama dan dapat melanjutkan memilih menu yang tampil pada sistem.

\subsection{Entity Relationship Diagram}

Gambar diatas menjelaskan relasi antar entitas atau tabel dalam database. Dimana setiap entitas memiliki atribut masing-masing dan saling terkait membentuk suatu hubungan. Dalam ERD dapat dirancang suatu model struktur data dan hubungan data tersebut. Sehingga memudahkan dalam pembuatan basis data, analisis sistem dan pengembangan sistem.

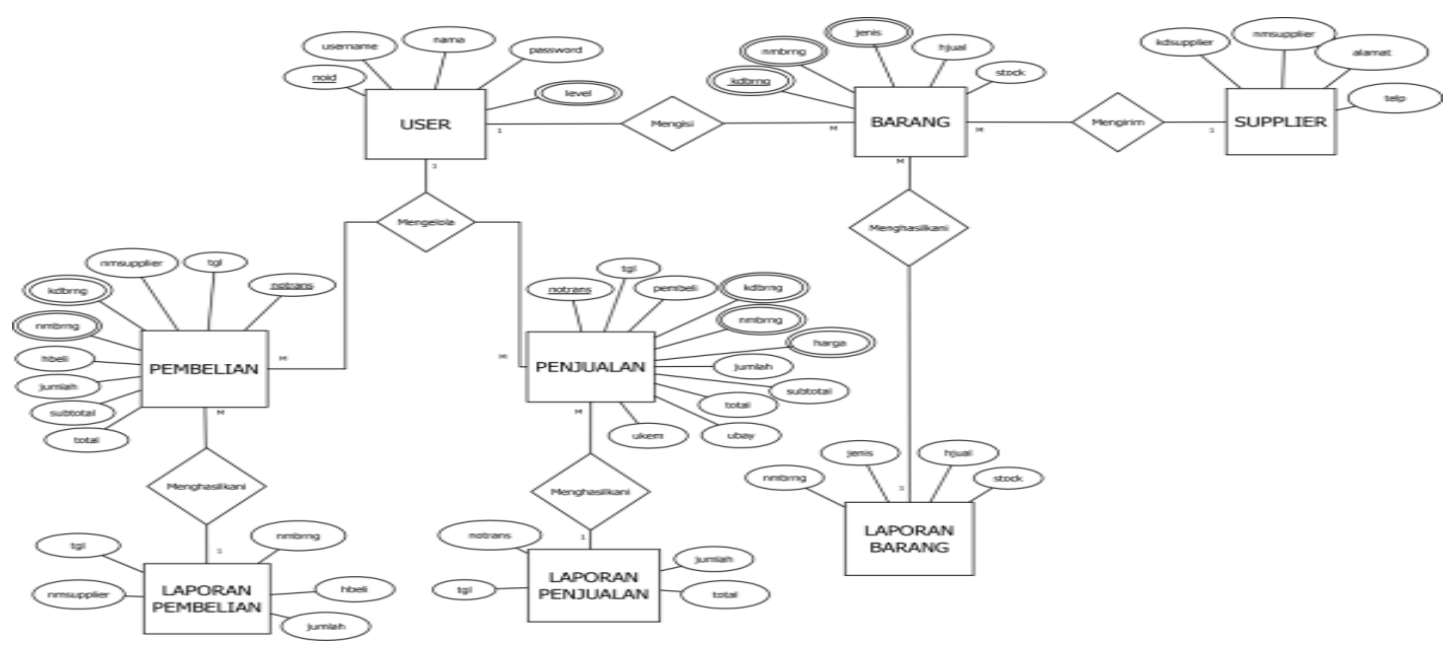

Gambar 4. Entity Relationship Diagram

\subsection{Logical Record Structure}

LRS merupakan representasi dari struktur record pada tabel-tabel yang terbentuk dari relasi antar himpunan entitas. LRS juga berfungsi untuk menentukan kardinalitas, jumlah tabel dan kunci tamu (Foreign Key). Dari gambar diatas terlihat kardinalitas yang ada yaitu one to one dan one to many.

Gambar 5. Logical Record Structure 
Building of Informatics, Technology and Science (BITS)

Volume 2, No 2, December 2020 Page 135-140

ISSN 2684-8910 (media cetak)

ISSN 2685-3310 (media online)

\subsection{Implementasi Program}

\section{a. Tampilan Program}

Pada Gambar 6. dijelaskan halaman menu utama. Dimana admin dapat mengelola semua data yang ada didalam sistem. Mengelola data barang, penjualan, pembelian dan supplier.

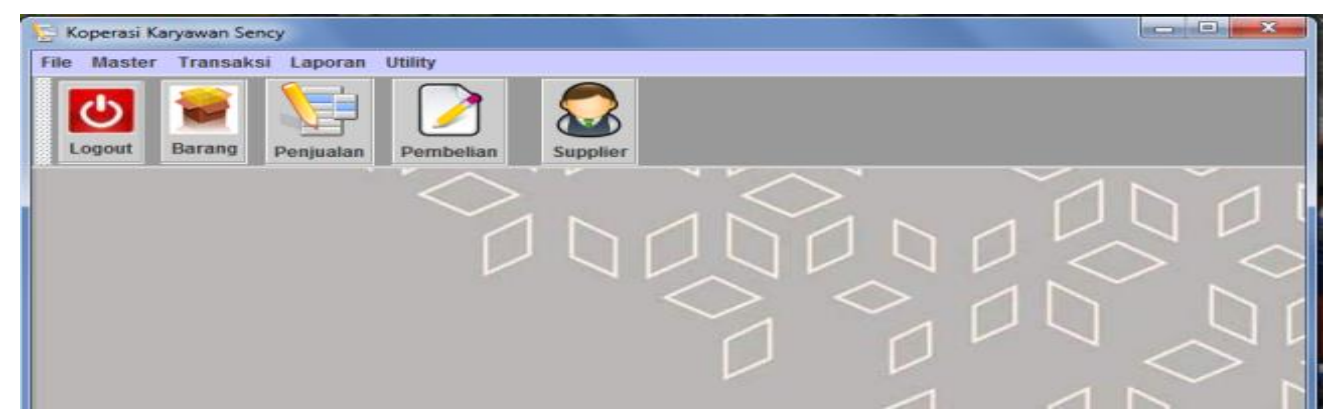

Gambar 6. Tampilan Menu Utama

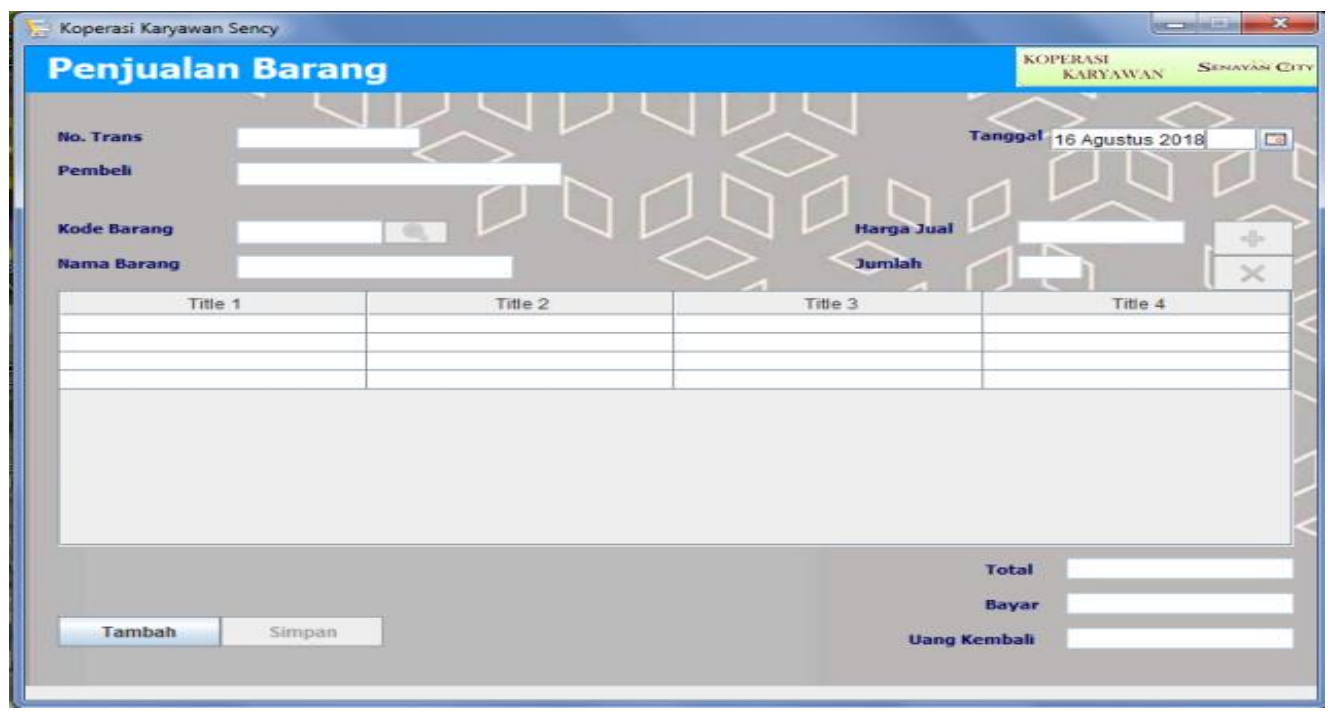

Gambar 7. Tampilan Menu Penjualan

Pada gambar 7 dijelaskan halaman menu penjualan. Dimana admin dapat mengelola semua data penjualan yang ada didalam sistem.

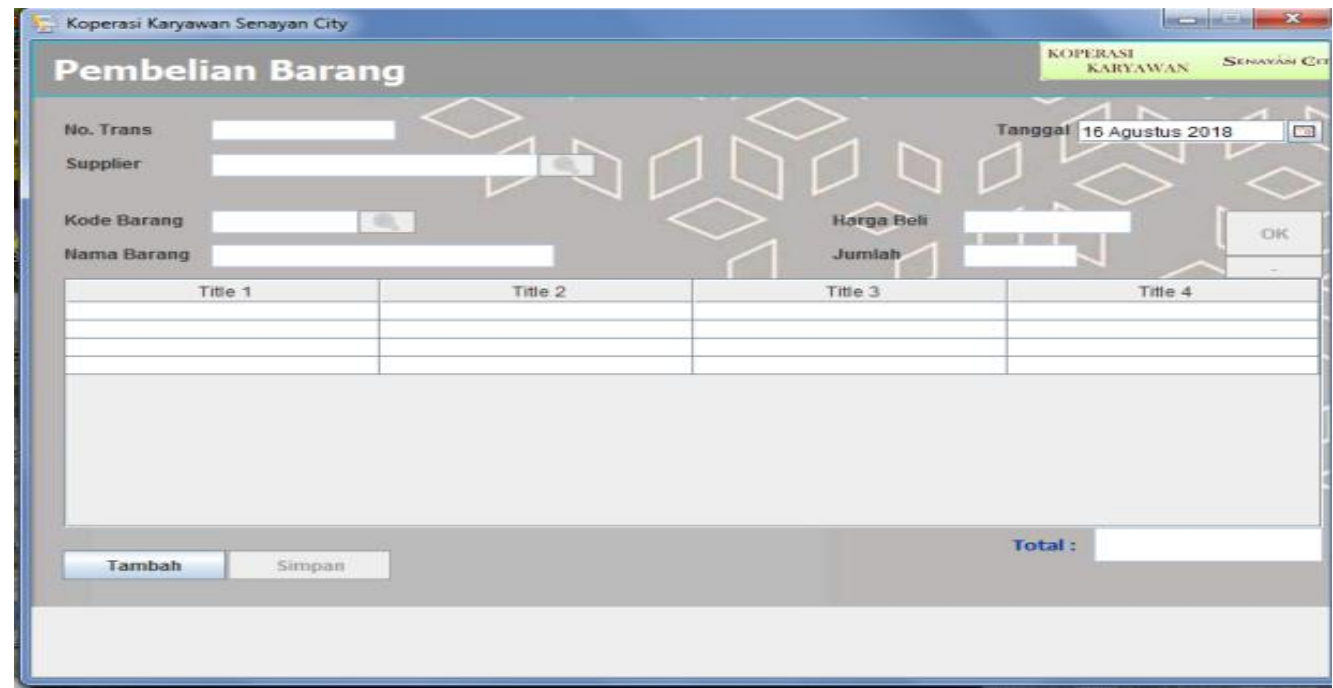

Gambar 8. Tampilan Menu Pembelian

Pada Gambar 8. dijelaskan halaman menu pembelian. Dimana admin dapat mengelola semua data pembelian yang ada didalam sistem. 


\section{KESIMPULAN}

Berdasarkan hasil penelitian, proses sistem berjalan pada Koperasi Karyawan Senayan City yang semula dilakukan secara manual, kini dapat dilakukan secara terkomputerisasi dan berjalan dengan baik. Dengan digunakannya sistem penjualan dan pembelian tersebut diharapkan pengelola Koperasi Karyawan Senayan City mendapat kemudahan dalam melakukan transaksi jual-beli pada unit usaha toko. Transaksi yang dilakukan saat ini dapat dipertanggungjawabkan secara sepenuhnya tanpa ada karaguan akan transaksi-transaksi yang tidak tercatat. Seluruh data tersimpan dengan baik disamping penyimpanan dalam bentuk kertas maupun penyimpanan data dalam bentuk file.

\section{REFERENCES}

[1] R. Anggraeni, Elisabet Yunaeti, Irviani, Pengantar Sistem Informasi, 1st ed. Yogyakarta: ANDI, 2017.

[2] F. Nursaman, Muhamad, Kusuma Astuti,Intan, Matondang, "APLIKASISISTEMINFORMASIKOPERASI KARYAWAN PADA PT.SURYA SIAM KERAMIK,” Semin. Nas. Teknol. Inf. dan Multimed. 2018, vol. 6, no. 2302-3805, pp. 1-6, 2018.

[3] W. P. Tampubolon, "Sistem Informasi Penjualan Barang Di Koperasi Pada Kantor Oditurat Militer I-02 Medan Berbasis Website," J. Tek. DAN Inform., vol. 5, no. 2089-5490, pp. 1-6, 2018

[4] Sunarti, "RANCANG BANGUN SISTEM PEMINJAMAN PADA KOPERASI HORTINA DIREKTORAT JENDERAL HORTIKULTURA JAKARTA," Indones. J. Comput. Inf. Technol., vol. 1, pp. 1-9, 2016.

[5] J. Hutahaean, Konsep Sistem Informasi. Deepublish, 2018.

[6] T. Sutabri, Analisis Sistem Informasi. Yogyakarta: Andi Offset, 2012.

[7] A. Mahatmyo, Sistem Informasi Akuntansi Suatu Pengantar. 2014.

[8] A. Hafiz and M. Ma'mur, "Sistem Pendukung Keputusan Pemilihan Karyawan Terbaik Dengan Pendekatan Weighted Product," Cendikia, vol. 15, no. 2, pp. 23-28, 2018. 